\title{
Does Training and Development Impact the Employee Performance or another Ritual
}

\author{
Nwali C. Ndidi ${ }^{1, *, \dagger}$ and Adekunle Moses ${ }^{2, \dagger}$ \\ ${ }^{1}$ Nnamdi Azikiwe University, Awka and ${ }^{2}$ Lagos State University, Lagos \\ *corresponding author: nwalichioma@yahoo.com \\ ${ }^{\dagger}$ Auhtors Contributed equally.
}

\begin{abstract}
Background: Today's competitive business environment requires that for organizations to survive the fierce competition in the business environment, the organization must invest heavily on human resources training and development to stay upto-date on the best industry business practices across the globe. One such way to improve and increase the available skill sets, knowledge, and capabilities of the employee to meet all the important needs of the organization customers is through training and development. Method Thus, this study evaluates the impacts of training and development on employee performance using quantitative research methods. To achieve the objectives of the study, the research a quantitative research design was employed, and a questionnaire research instrument was used in collecting relevant data from either owners or managers of 260 Small and Medium Scale Enterprises in Lagos Nigeria. Findings The study concludes that both off-the-job and on-the-job training are effective towards improving employee performance and that training and development not only improves the skill set of the employees but also a source of motivation for the employees.
\end{abstract}

Key words: Training and development; employee performance; Nigeria; On-the-job training; Off-the-job training.

\section{Introduction}

The customer needs are fast-changing, and organizations are increasingly facing fierce competition for their services and products which has increased the need for the employees to be better equipped with all the necessary skills and tools to deliver outstanding services to the customer. The area of human resources and human expertise proved to be a major issue and underlying reason for competition among the organizations. The role of humans has become the focus of the attention to the researcher and business sectors managers that the organizations need to develop their human resources to sustain their competitive edge (Baldwin and Johnson; 2008). The knowledge and skills of human resources safeguard organizational life. The updating the upgrading of these skills makes organizations able to adapt to the new environment that is almost subject to the constant charge. These facts had made managers understand the importance of training their human resources to improve the overall performance of the organizations (Dessler; 2003).

Managers like to measure the performance of their employees and improve it. While Technological innovation is gradually taking over, it is not only essential to be aware of these changes but to emphasize the need for training and implementation of such development. The absence of training can force employees out of relevance within an organization. Maimuna and Rashad (2013) shared the view that in the dynamic and evolving market that is highly turbulent and dynamic, an organization needs to focus on the development of its human capital with the intent of gaining competitive advantage. The success of an organization is a function of the number of skilled, experienced, and knowledgeable workforce at its disposal. Thus, to remain competitive in today's dynamic business environments, the organization must therefore rely heavily on training and development as growth strategies. It is equally important that employees at all levels are trained to ensure the required skills are available and at the same time 
available skills are not eroded (Maimuna and Rashad (2013).

Training and development are two different concepts that reinforce each other. For instance, while training is focused on the individual's "current job, in developing certain skillset, capabilities, and competence required to execute their job, development, on the other hand, focused in transforming the employee behaviour, attitude and characteristics that define his/her approach to work. The idea is to improve and enhance the employability skills in doing the job $\mathrm{s} / \mathrm{he}$ is employed to do. Training and development have become routine programmes in most organization human resources departments largely because of their importance to the performance of the employee (Mobarak et al.; 2019; Muogbo; 2013). As noted by Mohammed and Shouvik (2018) employee is viewed as the most treasurable asset at the disposal of any organization largely because of they have the capacity to build, develop or even destroy the organization depending on how they are managed and the available skill set.

Undoubtedly, training activities are a continuous human resources management function to facilitate the adaptation of employees for new conditions or environments, and also to increase decision-making and problem-solving capabilities in these environments. Training is an indicator of the importance given to the employees and constitutes an important wing of the investments made by people. In terms of employees, participation in training programs, of which expenses are covered by companies, can enable them to feel privileged and to increase their knowledge and skills(Kumari; 2014). In this way, they can perform their tasks more motivated without feeling lacking. There are many factors that affect employees' motivations. These can be summarized as economic, psychosocial and organizational and managerial tools. This study, it is aimed to reveal the effects of educational activities on employee motivation which are evaluated within the scope of organizational and managerial motivation tools (Ezeani and Oladele; 2013).

Training and development activities with motivation will be evaluated as two main variables. As argued by (Mobarak et al.; 2019), training's importance to the development of the employees cannot be overemphasized especially when we consider the fact that training equips the employee with the knowledge of a new way of getting a result and motivate the employee into the art of critical thinking.

In countries like Nigeria, where individuals are not exposed to formal work at an earlier stage to gain the requisite experience, it is very costly for the organization to train individuals without any fair knowledge of the workflow. The lack of sufficient experience and knowledge about what the organization does create more burden on the human resources department to train the workforce. This prompted Mohammed and Shouvik (2018) to argue that the problem with most organizations in developing countries like Nigeria is that the cost of training the workforce is high largely because the newly recruited employees have no previous experience unlike the western countries where even students are required to work as part of the graduation criteria to gain fair experience at the corporate world (Depo-Mogaji and Olowolaju; 2019).

(Nwachukwu; 1998) asserted that the importance of training and development cannot be overrated especially when we consider the fact that training motivates the employee into higher productivity through boosting the employee morale. Most employees view training as a motivational tool from the organization and an art of love from the employer who demonstrate they have interest in the development of the employee. The idea here is that when the employee is trained, they have more likelihood of assuming greater responsibilities which will most likely leads to higher pay. Redmond (2007) posit that an organization's work may have the necessary equipment, the appropriate environment, and be determined to work. However, productivity level falls, and this is because the workers lack the skill and knowledge, which could be through training. (Depo-Mogaji and Olowolaju; 2019) posit that the purpose of any training program should be to develop near talent and to update old ones. The adoption of training in organizational activities is a means of improving work performance. Like in most developed countries, Organizations that operate there have keyed into training with the rapid advancement of technological changes and seen it as a necessity in almost all walks of life. Some organizations adopt staff training to improve performance while others rule it as not relevant due to lack of funds or a non-necessity.

Should staff training, therefore, be seen as a part of an organization's corporate function, as an integral element in terms of corporate strategy? This study will also find out if staff training influences the performance of employees in an organization. Interestingly, most organization lost lots of customers because of using employees without much knowledge in attending to their customers (Ezeani and Oladele; 2013). Customers feel irritated and furious when inexperienced worker attends to them because they feel their time is wasted. This has the tendency of impacting the performance of the organization. Some organization in developing countries laments that the cost of training is high and cannot be afforded by the organization which perpetually cripple the potentials of the workers. This raise the question of how can training cost be reconciled with the training benefits and potentials?

Staff training is often required to anticipate and absorb future dynamism as change technological innovations are introduced regularly, which takes different shapes in its significance as well as in its pace. Another call for concern is that many organizations only emphasize the need for training but do not implement it. Thus, a peculiar and permanent feature for most workers. The absence of training can force employees out of the organization and spur them into looking for job elsewhere where they can be adequately trained, and their skills effectively developed and deployed. The aim of this study is to determine the extent training and development of employees impact the performance of the employees.

\section{Literature Review}

\subsection{The importance of Training and Development}

In a very competitive business community, what separates one organization from the rest is the performance of its workers. Organization always seeks to drive employee performance and productivity while utilizing various strategies in line with its Mission, Vision, and Objectives. These strategies range from selection, recruitment, and reward system to training and education of employees(Black and L.; 2002).

The competitive nature of the twenty first century business environment that requires more from the employee has increased the need for training and development of the employees. This according to Depo-Mogaji and Olowolaju (2019) is further necessitated by the technological advancement around the world and the need for creative and innovative ability of the employees to ensure value for money through quality products. In addition, the essence of employee training is to enable them to get the requisite skills and capabilities required 
for the delivery of their services to their organization. In the words of Mobarak et al. (2019) employee training entails getting the necessary knowledge about the work situation and the way to manipulate the technicalities of the work to achieve the required objectives. Accordingly, training and development improves the skills and know-how of the employees and is a very important aspect of an organization under the human resource management.

This improves the group and organizational performance of the employees. Another advantage of training and development is in its ability to increase the productivity of the organization through the on-the-job development of the employees on their actual duties in the organization (Baldwin and Johnson; 2008). It is pertinent to state that training and development of the employees should not be seen as honour to the employees that is common in developing countries like Nigeria with high incidence of informal economy(Tonuchi et al.; 2020) but a duty on the part of the managers of the organization to make training policies and execute them as part of the organization's action plans on employees immediately after their employment.

According to Happiness and Michael (2014), the role of training and development of the employees on every organization has called for constant need for its implementation for effective operations, and productivity. Research has shown that training of employees ensures improved performance and human capability and serves as a motivating factor on the part of the employees which leads to the achievement of the organization corporate objectives at minimal cost and time (Mohammed and Shouvik; 2018). According to Laing (2009), the essence of training of employees is to acquire higher skills as demanded by the constant business environmental changes and challenges which will make an organization perform better than before and outperform its rivals in the industry. In support of the above submission, Singh and Mohanty (2012) noted that the needed increase in the productivity of an organization can only be achieved through training of the employees for effective and efficient use of the resources for higher performance of the organization.

It is noteworthy that training ensure job satisfaction on the part of the employees and increase their morale for higher service delivery which leads to the success of the organization. The implication is that training and development facilitate the development of employee skills, competence, capabilities, and knowledge. Improvement in the employee's skill sets to boost the morale as they are made to be able to do more for the organization with a lesser resource compared to when they have not been trained. This means that training does not only benefit the employee through improved productivity but also the organization performance.

According to Ndibe (2014) training can be defined as a predetermined action plan for changing the work attitude of the employees in addition to their know-how in the job through practical on-the-job learning and on the many areas of the organizational activities for the purpose of achieving the mission and vision of the organization. Training systematically translates to organizational employees' productivity and hence, the organizations' performance. The continuous innovations and improvement in modern communication technology constantly reshapes the state of skills and knowledge and therefore need to be updated in order not to be out of date based on business dynamics. It is evident that with less supervision of the employees, an experienced employee knows what to do at any given time and this leads to reduction in the cost, time, and errors in operation because of the availability of the required knowledge for effective services delivery as a result of training.

\subsection{Human Resource Planning}

According to (Redmond; 2007), the concept of human resource planning is meant to identify and analyse the existing human resource in an organization and use the outcome of the analysis to plan against the organizations' future human resource needs and challenges for the purpose of sustained operations.

\subsubsection{The processes involved in Human Resource Planning}

For effective and efficient planning of an organizations human resources, four steps have been identified as a necessity which the planners of the training should follow as listed below.

1. The planner is expected to examine the existing organizational human resource. This includes total appraisal and identification of the strength and weakness of the existing human resources and personal and academic details of the employees. This includes the skills acquired and the skills required, the academic requirement of the labour force, the terms of employment of the respective employees, and the remuneration of the employees.

2. Forecast Future HR Requirements: the second step demand that the planners of the human resource should identify in futuristic terms is the needed human resources of the organization, their, skills, academic, knowledge, and experience requirements, and how and where they will be utilized for future performance of the organization. to achieve this, the managers look into the futuristic challenges and changes in market conditions, including the rate of changes in the technology and production process and positions the organization beforehand. 3. Identification of organizational human resources gaps: a good HR plan considers supply and demand. Using HR forecast to identify the future gap in the skill to be required in the organization, asking relevant questions as upping the skill of existing employees or recruiting qualified employees in specific areas?

4. Making the HR plan part of the organization's strategy: to make a human resource plan easy for implementation, it is required that it should be integrated in the policies and strategies of the organization and appropriate measures put in place for its execution such as finance through budgetary allocation.

\subsection{Staff Training}

Training of employees can be defined as activities carried out by an organization for the purpose of improving the ability of the employees to deliver his services effectively and efficiently. In the other words, training involves increasing the job experiences, skills and knowledge of an employee for improved performance.

\subsubsection{Purpose of Training}

The general essence of training involves knowledge and skills acquisition which can be used to achieve three specific goals, namely:

\footnotetext{
- To enhance the skill and capability of the employee in the areas of service delivery.

- To improve employee's level of self-awareness about the job requirements.

- To increase an individual's level of motivation to perform his or her job.
}

Commonly, employee's training guides him to develop the required skills and ensures that the employee acquires the needed competence for self-dependence in his workplace. Sending employees on training courses should be based on the perceived genuine needs of the individual concerned and who also has realized the overall needs and objectives of the 
organization.

In the words of Dessler (2003), training of employees is one of the standards for judging the managerial abilities of the managers of organizations and those who don't consider it relevant in their organizations do so at their peril. The author further submitted that the success of an organization does not depend on the numerical strength of the workforce, but on the ability of the available workforce to deliver the required services. Proper training is an effective performance enhancer. In addition to this, it is evident that the profitability of an organization is a function of the organization's workforce competences and capabilities. According to Olaniyan and Ojo (2008) it is believed that the market attractiveness and corporate reputation of an organization depends on the quality of its employees expressed through their ability to deliver satisfactory services to their consumers and customers.

\subsubsection{Determining Training Needs}

It is a fact that for an organization to be competitive in today's challenging business environment, the employment of educated and trained staff for the purpose of service delivery is paramount. In the words of Depo-Mogaji and Olowolaju (2019) for a training program to be carried out, there is need for the assessment of the corporate human resource needs of the organization before selecting those to be trained and in the areas where the training is required. The competition occasioned by globalisation has made staff training a major tool for competitive performance of firms and for higher profitability.

The process of identification of training needs starts with the immediate supervisor of the worker who reports to the lead of training to engage such workers for training. It is noteworthy that the need for training of employees can be caused by a gap in the performance of the employees. This means that when there is obvious gap between the expected outcome and the actual performance of the employees, it indicates that there is need for training. There are four procedures that managers can use to determine the training needs of employees in their organizations (Happiness and Michael; 2014; Baldwin and Johnson; 2008; Dessler; 2003):

- Examining the Job Requirements: the managers are expected to examine the required competences for a given job description and identify the staff who are not qualified amongst the workforce and slate them for training.

- Analyze the Organization: on this procedure, the internal operations of the organization are re-evaluated and point where there is lapses identified for training to ensure effective performance. The point of lapses can manifest through low output, high cost for rendering a small service, high turnover of staff.

- Performance Appraisals: through performance appraisal, the output an employee is measured using the stated standards that will need to the desired objective. Any variance between the performance and the output or standard, calls for training.

- Conducting a survey on the human resources: through the survey procedure, the employees including the managers are given the opportunity to air their views on their workplace conditions and suggest the possible ways of solving the problems identified at their workplace.

\subsubsection{Methods of Training}

According to Ezigbo (2011), the essence of on-the-job training is to ensure that the employee learns the improved ways of delivering the services while performing his duty under a trainer who teaches him the new skills. This means that the method ensure that the employee learns through practice of the learning process in his duty post. It is expected that the trainees are acquainted with the new ways of service delivery within the time allocated for the training. This training can be in the area of use of improved technology such as biotechnology, computer, modern equipment as the work demands, modern method of keeping record and use of software for data analysis. Evidently, training exposes the employee to the best method of tackling the challenges associated with his workplace situations. On the job training can be carried out through the following ways:

- Apprenticeship: according to Ezigbo (2011), this provides the trainee with the opportunity to acquire the needed skills and knowledge on a given craft or art.

- Induction/orientation: As submitted by Olaniyan and Ojo (2008), induction and orientation is meant to give the new candidates in the profession the require code of conduct in the practice of the profession and familiarize them with the needed and necessary environment of the corporation.

- Coaching/understudy: According to Ezeigbo (2011), this method is applied when an employee is to take the office of his trainer (boss). Within the period and a process of handover, the individual works under the boss while he coaches the individual on the ways of rendering the service in the office.

- Internship: this method is practiced mostly by public and professional bodies while on the job. Internship are practiced by professional bodies such as medical doctors and it is equivalent to apprenticeship practiced by the trainers and the trainee on craft and other vocations.

- Job rotation: in the method of job rotation, trainees are assigned and reassigned to different duties in other to acquire the need skills in various areas of the duty within the time of the training. Job rotation method ensures that the experience and skill of the trainees are widened through the practice and within the time allocated for the training.

Off-the-job training. The essence of off the job training is to improve the experiences, skills, knowledge and competences of the trainee in the areas of employment which is different from the employee's workplace and conditions. The major purpose of allowing the trainee to get the training outside the job is to enables him or her focus his attention on learning the theoretical aspect of the work situation. This training can be likened to classroom learning and there is time allocated for the learning which allows the trainee to express their views during the session. Some examples of off-the-job training are those carried pout through seminars and symposium, conferences, and lectures. Others includes the lectures obtained through audio and video records. These experiences guide the trainee when carrying out his work on the job.

\section{Methodology}

The study employed a quantitative method to collect relevant data from 260 SMEs owners and managers in Nigeria. In particular, the study aims at collecting data to determine certain characteristics of a group. The study used a survey method using structured questionnaire developed based on literature construct to measure the relationship between training activities and employee performance.

The questionnaire is the instrument used in collecting primary data relating to the question under study. The instrument is structure in a manner that ensures its validity and addresses 
Table 1. Demographic Information

\begin{tabular}{ll}
\hline Items & Percentage \\
\hline Age & \\
$18-25$ years & $38.1 \%$ \\
$26-35$ years & $31 \%$ \\
$36-45$ years & $3.5 \%$ \\
46 years and above & $27.4 \%$ \\
Gender & \\
Male & $60.7 \%$ \\
Female & $39.3 \%$ \\
Education Qualification & \\
SSCE/OND & $4.3 \%$ \\
BSc & $56 \%$ \\
MSc & $38.8 \%$ \\
PhD & $1 \%$ \\
\hline
\end{tabular}

Source: Authors

the purpose of the study. This means that the questions on the questionnaire are structured and drafted in the way that the answers to be gotten as responses from participants should be able to lead to achieving the objective of the research. The survey questionnaire instrument is close-ended since the research follows the part of positivism given the research objectives and strategy. Close-ended questions allow the researcher the easy freedom to evaluate the research assignment. In the words of Rubin and Rubin (2005), close-ended questionnaire reduces time need to be spent on a given question and increases the speed of obtaining information from the respondents, therefore, the questions need to be in clear and simple terms for easy understanding and answer.

The sample respondents were randomly selected from SMEs offering services in Lagos state Nigeria. Lagos is considered the busiest city in Nigeria and houses the greatest percentage of SMEs in the country. To guarantee the relevance of the questionnaire, the researcher ensure that the constructs is developed based on existing literature. Secondly, a pilot study was conducted with an average Cronbach Alfa of 0.86 which is considered adequate based on existing literature (Ridwan and Joseph; 2021).

\section{Result and Discussion}

260 questionnaires were distributed randomly to the respondents and 247 questionnaires were correctly filled and retrieved representing 95 percent response rate. Creswell (2014) viewed a response rate of 40 to 50 percent adequate for an online survey. The data in Table 1 reveals that $38.1 \%$ of the respondents are between age $36-45$ years, $31 \%$ are $26-35$ years, $27.4 \%$ are 46 years and above, while the remaining $3.5 \%$ are $18-25$ years. This lay credence to the fact that most of the opinion sampled is within the active working-age group. Interestingly, 60.7 percent of the total respondents are male while the remaining 39.3 percent of the respondents are female. 56 percent of the respondents are BSc holders, this was closely followed by the holders of master's degree which represent 38.8 percent while only about 4.3 percent are SSCE/HND holders and lastly 1 percent of the sampled respondents hold $\mathrm{PhD}$.

\subsection{Training and Development roles on employee per- formance}

It was revealed that 70.7 percent of the respondents strongly subscribe to the idea that training should be made compulsory to all newly employed staff of the organization and not optional or sectional for some employees. This was followed by those who agree to the statement which represents only 19.8 percent of the total respondents. Interestingly, none of the respondents were neutral or merely disagree with the statement but 9.5 percent of the respondents strongly stand against the idea of training every new staff of the organization. The findings are in consensus with the general believed held in literature. For instance, Mobarak et al. (2019) noted that employees should from time to time be involved in rigorous training and development to ensure that the organization remains competitive in the industry especially the newly recruited staff. The author argued that the organization will be mismanaging it greatest asset without embarking on training for the newly employed staff.

On the reason why employees should be trained, it was revealed in Figure 1 that 69 percent of the respondents noted that employee should be trained because it affords more opportunities to acquire more skills, improves their capability and productivity level. Maimuna and Rashad (2013) shared the view that in a competitive and fast-changing business environment where customer demand more within the shortest time and with the integration of the global economy into one village slow and steady will no longer win the race but the responsive, innovative and technology-driven organization will stand the chance of winning the race.

It was discovered that 62.1 percent of the respondents strongly agreed with the opinion that employee training improves the quality of services rendered in the organization, 34.5 percent of the population merely agreed that employee training improve quality of services in the organization, 2.6 percent were undecided and 0.9 percent strongly disagree with the assertion. Mohammed and Shouvik (2018) noted that employees who are trained perform better than those who did not pass through any formal training when employed in the organization like what was discovered in this very study. The intuition is that when employee is trained on how to handle customers for instance, they will improve the services rendered to customer and as such improve the organization performance. Similarly, when the researcher enquired the extent training improves employee performance on the job. It was discovered that 75.8 percent of the sampled respondents strongly agreed that training improves performance on the job, 24.2 percent of the respondents agreed that training improves employee job performance and 1 respondent is undecided.

\subsection{Staff training, employee's job satisfaction, and or- ganizational performance}

The study revealed that 66.4 percent of the respondents strongly believe that training improved the performance of the employees, attitude, and competence level. It was also revealing that training excites the workforce because it improves their skills and knowledge making the employee more productive. The intuition behind this is simple, as employees get more training their skill improves, they gain more knowledge and lastly, they tend to enjoy salary increase and promotion as their productivity level will increase drastically. On whether financial and non-financial rewards motivate employees for improved performance within the organization, it was discovered that as much as 88.8 percent said rewards whether financial or non-financial improves employee performance within the organization. Only 11.2 percent said they are not sure of what to say and none of the respondents said categorically that rewards do not motivate employees for higher productivity. The finding is consistence with the assertion of earlier literature. For instance, Muogbo (2013) asserted that the highest way to motivate the employee for higher productivity is through both 
Table 2. Model Summary

\begin{tabular}{lllll}
\hline Model & $\mathrm{R}$ & $\mathrm{R}-\mathrm{Square}$ & Adjusted R-Square & Std. Error of the Estimate \\
\hline 1 & $.949^{a}$ & .900 & .894 & .108 \\
\hline
\end{tabular}

a. Predictors: (Constant), QE17, QE8, QE16, QE9, QE6, QE7

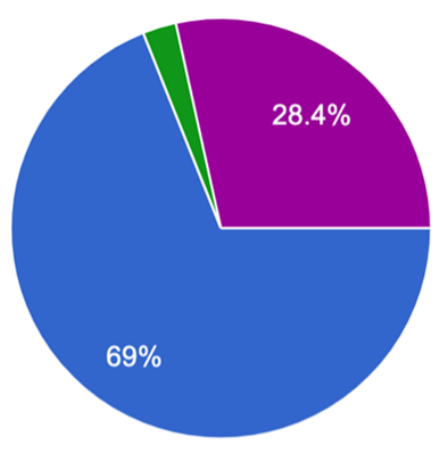

Figure 1. Why do employee go for training

Table 3. Regression Result

\begin{tabular}{lllll}
\hline Model & $\operatorname{Beta}(\beta)$ & Std. Error & T-statistics & P-value \\
\hline (Constant) & -.542 & .060 & -9.092 & .000 \\
QE6 & .089 & .018 & 5.054 & .000 \\
QE7 & .118 & .022 & 5.430 & .000 \\
QE8 & -.004 & .016 & -.264 & .793 \\
QE9 & .009 & .017 & .523 & .602 \\
QE16 & .095 & .021 & 4.447 & .000 \\
QE17 & .057 & .014 & 4.211 & .000 \\
\hline
\end{tabular}

monetary and non-monetary rewards in the form of increased salary, recognition, job security among others. Kumari (2014) all view reward either monetary or non-monetary as great motivator of employees towards higher productivity.

To validate the findings, the study conducted regression analysis to empirically determine whether training improves the performance of the employees or not. It was revealed as presented in Table 1 that there is high correlation between employee performance and training and development. In particular, Table 3 that off-the-job training like lectures, seminars, conferences, on-the-job training like coaching, mentoring, understudy, financial and non-financial rewards, and lastly post staffing training have significant impact on employee performance given that their $\mathrm{p}$-value are less than 5 percent level of significance or since the $t$-test calculated is greater than 1.86. Similarly, the R-square is 0.949 which means that about 94.9 percent of the changes in employee performance is accounted for by training and development.

Both off-the-job and on-the-job training significantly impacts employee performance. The intuition behind the respondents ranking it first among all the construct with the highest impact on the employee performance might be due to the fact that off-the-job training often present the employees opportunities to meet people from different organization and learn more about things not within the organization especially the top management executives. Similarly, it present opportunities for the employees to enjoy training allowance unlike other kind of training especially in countries like Nigeria.
To acquire more skills and improve employees competence and perfor...

To improve employees financial wellbeing

To prepare employees for promotion within the organization

To achieve organizational aims and objectives

To promote both the experience of the employee and the profile of the org...

\section{Conclusion}

The findings of this study revealed that training and development have positive relationship and a strong positive influence on employee's performance and productivity. Benefits are obvious if training programs and development plans are devised which fit the trainees, the job description, the managers and supervisors, and their different levels of education and background appropriately and go in line with the company's goals and objectives.

Therefore, investing in training and development is imperative for any organization, which will certainly realize returns on its investment in training and developing its workers. Moreover, effective development programs allow for the organization to maintain a workforce that can adequately replace employees who may leave the company or who are moved to other areas. On the individual level employees are encouraged to carry out self-assessment, where they are expected to identify their opportunities and needs for improvement.

The importance of training of staff is further reinforced when we discovered that trained employees improve teamwork and harmony within the organization as the employees tend to have similar orientation and views about the methods of achieving the organizational goals and objectives. The researcher can conclude that training and development programs are very much important in order to achieve excellence and competencies in knowledge, skills, ability, potential, attitude and behaviour so than to meet rapid changes in technology and changes in work practices.

\section{Competing Interests}

Authors declare no competing interest.

\section{References}

Baldwin, J. and Johnson, J. (2008). Human capital development and innovation: The Case of Training in Firms, New York: Mc- 
Grawhill.

Black, S. and L., L. (2002). How to compete: The impact of workplace practices and information technology on productivity, Review of Economic and Statistics 83(3): 1-13.

Creswell, J. W. (2014). Research design: Qualitative, quantitative and mixed methods approaches (4th ed.), Thousand Oaks,CA: Sage.

Depo-Mogaji, T. O. and Olowolaju, P. S. (2019). Effect of employee training on profitability of deposit money banks in nigeria, International Journal of Scientific and Engineering Research 10(1): 1-8.

Dessler, G. (2003). Human resource management, Cambridge: McGraw Hill Publishers.

Ezeani, N. S. and Oladele, R. (2013). Implication of training and development programmes on accountants' productivity in selected business organisations in onitsha anambra state, nigeria, International Journal of Asian Social Science, Asian Economic and Social Society 3(1): 266-281.

Ezigbo, C. A. (2011). Advanced management: Theory and applications, Enugu: Immaculate Publication Limited.

Happiness, O. O. and Michael, C. E. (2014). Impact of training and development on organizational effectiveness: evidence from selected public sector organizations in nigeria, European Journal of Business and Management 6(29): 66-75.

Kumari, N. (2014). Using performance appraisal as an effective tool for motivating employee performance: a live study, Business Perspectives and Research 2(2): 37-46.

Laing, I. F. (2009). The impact of training and development on work performance and productivity in public sectors organizations: A case study of Ghana Ports and Garbous authority, Kwame Nkrumah University of Science, and Technology: Ghana.

Maimuna, M. N. and Rashad, Y. F. (2013). The impact of employee training and development on employee produc-

Tonuchi, J., Peters, I., Adetoba, T. and Oluwaseun, M. (2020). How large is the size of nigeria's informal economy? a tivity, Global Journal of Commerce and Management Perspective 2(6): 91-93.

Mobarak, K., Musfiq, M. C. and Walib, B. L. (2019). The impact of training and development on employees' performance: An analysis of quantitative data, Noble International Journal of Business and Management Research 3(2): 25-33.

Mohammed, W. H. and Shouvik, S. (2018). Impact of training and development on employee performance: a comparative study on select banks in sultanate of oman, Research Journal of Finance and Accounting 9(6): 1-12.

Muogbo, U. S. (2013). The impact of employee motivation on organisational performance: A study of some selected firms in anambra state, International Journal of Engineering and Science 2(7): 70-80.

Ndibe, B. C. (2014). Effect of employees training on organizational performance in soft drinks bottling companies in Enugu State, Nigeria, University of Nigeria: Nsukka.

Nwachukwu, Z. (1998). Management theory and practice, Ibadan: African EFP Publishers.

Olaniyan, D. A. and Ojo, L. B. (2008). Staff training and development: a vital tool for organisational effectiveness, European Journal of Scientific Research 24(3): 326-331.

Redmond, H. (2007). Human resource management: $M$ and $E$ Handbook, London: McDonald and Evans Limited.

Ridwan, D. and Joseph, E. T. (2021). Effects of bank charges on bank's customers saving and income in nigeria, Journal of Economics, Management 27(3): 1-11.

URL: DOI: $10.9734 / J E M T / 2021 / v 27 i 330331$

Rubin, H. J. and Rubin, I. S. (2005). Qualitative interviewing: The art of hearing data, (2nd ed)., Thousand Oaks,CA: Sage.

Singh, R. and Mohanty, M. (2012). Impact of training practices on employee productivity: A comparative study., Inter science Management Review 2(2): 2231-1513. mimic approach, 8(7): 204-228. 